\title{
Veronica Bonanni, "Une critique à courte vue». Strategie polemiche nelle "Préfaces" di Balzac
}

\section{Marco Stupazzoni}

\section{(2) OpenEdition}

1 Journals

\section{Edizione digitale}

URL: http://journals.openedition.org/studifrancesi/6018

DOI: $10.4000 /$ studifrancesi.6018

ISSN: 2421-5856

\section{Editore}

Rosenberg \& Sellier

\section{Edizione cartacea}

Data di pubblicazione: 1 mai 2011

Paginazione: 189

ISSN: 0039-2944

\section{Notizia bibliografica digitale}

Marco Stupazzoni, «Veronica Bonanni, «Une critique à courte vue». Strategie polemiche nelle "Préfaces" di Balzac», Studi Francesi [Online], 163 (LV | I) | 2011, online dal 30 novembre 2015, consultato il 10 janvier 2021. URL: http://journals.openedition.org/studifrancesi/6018 ; DOI: https://doi.org/10.4000/

studifrancesi.6018

Questo documento è stato generato automaticamente il 10 janvier 2021.

\section{(c) (1)}

Studi Francesi è distribuita con Licenza Creative Commons Attribuzione - Non commerciale - Non opere derivate 4.0 Internazionale. 


\title{
Veronica Bonanni, «Une critique à courte vue». Strategie polemiche nelle "Préfaces" di Balzac
}

\author{
Marco Stupazzoni
}

\section{NOTIZIA}

VERONICA BONANNI, «Une critique à courte vue». Strategie polemiche nelle "Préfaces" di Balzac, in AA. VV., Il Discorso polemico. Controversia, invettiva, "pamphlet"; Atti del XXXIII Convegno Interuniversitario (Bressanone/Brixen, 7-10 luglio 2005), a cura di Gianfelice PERON e Alvise ANDREOSE, Padova, Esedra editrice, 2010, «Quaderni del Circolo Filologico Linguistico Padovano», pp. 259-267.

1 Le Préfaces ai romanzi della Comédie humaine rivestono un importante valore teoricoprogrammatico e rappresentano parimenti lo specchio fedele e "preso dal vivo" del progetto-Comédie humaine nel suo divenire. L'esigenza, dichiaratamente polemica, di far precedere o seguire quasi ogni romanzo o racconto da uno spazio di scrittura paratestuale il cui carattere contingente e provvisorio e la "verve" stilistica fanno pensare più ad un articolo giornalistico che ad una pre/postfazione vera e propria, è determinata dalle continue accuse portate da una critica spesso miope nei confronti della struttura dell'opera e della sua moralità. In questo studio, V. Bonanni evidenzia in modo efficace lo scarto esistente tra «la prospettiva di Balzac e quella della critica nel guardare a quest'opera in corso di costruzione» (p. 263) dal punto di vista dell'unità architettonica dell'insieme entro cui si inseriscono, in armonia oppure in contrasto tra loro, i singoli frammenti narrativi. Questo stesso principio spiega e giustifica, allo stesso tempo, la "mise en scène" di figure morali e immorali, la rappresentazione, lontana da ogni idealismo, di personaggi non assoluti, ma relativi ed in continua relazione tra loro. Queste strategie di difesa adottate nelle prefazioni ai singoli romanzi saranno abbandonate da Balzac solamente quando l'edificio letterario conoscerà il suo assetto 
(quasi) definitivo: sarà infatti l'Avant-propos del 1842 a presentare alcuni principî generali compatibili con l'opera finita: le polemiche, le osservazioni e le giustificazioni contenute nelle singole "préfaces" «andavano quindi escluse in quanto elementi circostanziali, passeggeri e provvisori; ma anche naturalmente in quanto scomodi testimoni della frammentarietà e dell'incoerenza dell'opera nel suo farsi» (p. 267). 